\title{
DISCURSIVIZAÇÃO SOBRE "DOENÇAS DO NÃO APRENDER" NO CONTEXTO EDUCACIONAL INCLUSIVO: O QUE DIZEM OS PROFESSORES DE EDUCAÇÃO INFANTIL? ${ }^{1}$
}

\author{
DISCURSIVIZACIÓN SOBRE LAS “ENFERMEDADES DEL NO APRENDER” EN EL \\ CONTEXTO EDUCACIONAL INCLUSIVO: ¿QUÉ DICEN LOS PROFESORES DE \\ EDUCACIÓN INFANTIL?
}

\author{
DISCUSSION ON “DISEASES OF NOT LEARNIN” THE INCLUSIVE \\ EDUCATIONAL CONTEXT: WHAT DO EARLY CHILDHOOD \\ EDUCATION TEACHERS SAY?
}

Claudia Regina Mosca GIROTO ${ }^{2}$

Luciana Aparecida de ARAUJO ${ }^{3}$

Fabiana Cristina Frigieri de VITTA ${ }^{4}$

\begin{abstract}
RESUMO: Frente ao excessivo aumento de encaminhamentos e diagnósticos que resultam em "doenças do não aprender", esse estudo objetivou compreender como cinco professoras que lecionam para turmas do Infantil II, numa escola municipal de Educação Infantil, discursivizam as "doenças do não aprender" e as possíveis implicações em sua prática docente. A geração de dados se deu a partir da dialogia empreendida num fórum virtual de discussão, cujos dados indiciaram eixos de análise voltados às concepções sobre "doenças do não aprender" e à prática docente frente a tais "doenças". Os enunciados gerados revelaram o pensar e o agir desses professores submetidos à lógica medicalizante, em detrimento da valorização das diferenças inerentes à heterogeneidade na Educação Infantil.
\end{abstract}

PALAVRAS-CHAVE: Inclusão. Educação Infantil. Doenças do não aprender. Formação docente.

RESUMEN: Frente al excesivo aumento de encaminamientos y diagnósticos que resultan en "enfermedades del no aprender", ese estudio objetivó comprender como cinco profesoras que enseñan para las clases del Infantil II, en una escuela municipal de Educación Infantil,

\footnotetext{
${ }^{1}$ Os dados aqui considerados encontram-se vinculados ao Projeto CNPq Processo $n^{\circ} 406241 / 2016-3$, ao qual as autoras se encontram vinculadas.

${ }^{2}$ Universidade Estadual Paulista (UNESP), Marília - SP - Brasil. Docente do Programa de Pós-Graduação em Educação (PPGE) e do Departamento de Educação Especial, Faculdade de Filosofia e Ciências (FFC). Docente do Programa de Pós-Graduação em Educação Escolar (PPGEE), Faculdade de Ciências e Letras (FCLAr). Doutora em Educação. ORCID: <https://orcid.org/0000-0001-6267-8085>. E-mail: claudia.mosca@unesp.br ${ }^{3}$ Universidade Estadual Paulista (UNESP), Marília - SP - Brasil. Docente do Programa de Pós-Graduação em Educação (PPGE) e do Departamento de Didática, Faculdade de Filosofia e Ciências (FFC). Doutora em Educação. ORCID: <https://orcid.org/0000-0003-1147-5039>. E-mail: luciana.penitente@unesp.br

${ }^{4}$ Universidade Estadual Paulista (UNESP), Marília - SP - Brasil. Docente do Departamento de Educação Especial, Faculdade de Filosofia e Ciências (FFC) e do Programa de Pós-Graduação em Educação Escolar (PPGEE), Faculdade de Ciências e Letras (FCLAr). Doutora em Educação Especial. ORCID: <https://orcid.org/0000-0001-9545-7588>.E-mail: fabiana.vitta@unesp.br
} 
pronuncian alocuciones sobre las "enfermedades del no aprender" y las posibles implicaciones en su práctica docente La generación de datos se dio a partir de la dialogía emprendida en un foro virtual de discusión, cuyos datos indiciaron ejes de análisis volcados a las concepciones sobre "enfermedades del no aprender" ya la práctica docente frente a tales "enfermedades". Los enunciados generados revelaron el pensar y el actuar de esos profesores sometidos a la lógica medicalizante, en detrimento de la valorización de las diferencias inherentes a la heterogeneidad en la Educación Infantil.

PALABRAS CLAVE: Inclusión. Educación Infantil. Enfermedades del no aprender. Formación docente.

ABSTRACT: Due to the excessive increase of referrals and diagnoses that result in "diseases of not learn", this study aimed to understand how five teachers who teach kindergarten classes, in a municipal Early Childhood Education school, discourse the "diseases doen learning" and the possible implications in their teaching practice. The data generation was based on the dialogue undertaken in a virtual discussion forum, which data indicated axes of analysis focused on the conceptions about "diseases of not learn "and the teaching practice of such "diseases". The statements generated revealed the thinking and action of these teachers submitted to the medical logic, in the detriment valuation of inherent differences to the heterogeneity in Early Childhood Education.

KEYWORDS: Inclusion. Early childhood education. Diseases doen learning. Teacher training.

\section{Introdução}

A temática das "doenças do não aprender" tem sido discursivizada sob diferentes vertentes teórico-metodológicas e figurado também numa perspectiva crítica, nas publicações das áreas da educação, da saúde, da linguística, da sociologia, entre outras (CHRISTOFARI, 2014; FRANCES, 2016; MARQUES, 2018).

Ainda que, mais recentemente, isso venha ocorrendo numa perspectiva mais crítica, essa discursivização, que constitui o processo de construção discursiva carregada de valores sociais, históricos e ideológicos refratados nos/pelos discursos sobre as "doenças do não aprender", tem sido gerada, predominantemente, sob um ideal de normalidade tomado como homogeneidade e apagamento das diferenças.

Sob esse ideal de normalidade encontram-se assentados processos normalizadores constituídos a partir da tipificação social de comportamentos, valores, conhecimentos, a depender do prestígio político, social, econômico, linguístico assumido pelos grupos sociais, ao longo da história da humanidade, que, sob o discurso da norma, fortalecem a normalização do agir e do pensar (CANGUILHEM, 2007). 
Dessa normalização, em que não há lugar para o singular, para o diferente, resulta, invariavelmente, a estigmatização dos distintos modos de apropriação do conhecimento que, por não corresponderem a esse ideal, frequentemente são compreendidos, no campo da educação, como sintomas de doenças, num processo de naturalização das diferenças e individualização de questões que perpassam a apropriação da linguagem escrita. Questões essas que não se reduzem simplesmente a aspectos individuais e orgânicos, pois se encontram atreladas a determinantes sociais, políticos, ideológicos, econômicos, culturais, os quais engendram as condições materiais e subjetivas de vida sob as quais as desigualdades sociais são produzidas (GIROTO, 2006; GUARRIDO, 2010; MOYSÉS; COLLARES, 2013; GIROTO; BERBERIAN; SANTANA, 2014).

Ao considerarmos que os sistemas educacionais têm sido organizados na perspectiva da educação inclusiva, no cenário educacional brasileiro (BRASIL, 2008), tendo a universalização do acesso à educação, a igualdade de direitos no acesso às oportunidades e à equidade como princípios fundantes dessa perspectiva, dadas as singularidades que constituem o público escolar, há de se esperar que a heterogeneidade desse público, dos distintos modos de apropriação do conhecimento e dos contextos escolares seja levada em conta, no que tange aos processos educativos.

Os processos educativos têm sido determinados pela complexificação dos modos de organização social e de produção da existência humana, no que diz respeito à superação do caráter doméstico, em prol da institucionalização do trabalho educativo (SAVIANI, 1991), que necessita ser suficientemente diversificado e voltado à garantia do direito à educação de qualidade, ao longo do processo de escolarização, com vistas à apropriação dos conhecimentos culturalmente veiculados na/pela sociedade.

Nesse sentido, o trabalho educativo pode ser caracterizado como "[...] o ato de produzir, direta e intencionalmente em cada indivíduo singular, a humanidade que é produzida histórica e coletivamente pelo conjunto dos homens" (SAVIANI, 1991, p. 19). Assim, o saber produzido historicamente pela humanidade constitui-se em matéria-prima para o trabalho educativo que, por sua vez, constitui-se nas/pelas práticas sociais, mediadas na/com/pela linguagem, nas diferentes esferas da atividade humana (VIGOTSKI, 2010).

No que tange à Educação Infantil, isso implica reconhecer que o trabalho educativo deve respeitar as especificidades da criança que, do lugar de produtora de cultura e sujeito de direitos, precisa ter assegurado o “[...] direito a uma educação que reconheça a infância como uma construção da qual ela participa como ator social” (BAPTISTA, 2010, p. 5). 
Assim como o trabalho com a linguagem escrita, compreendida como prática social discursiva requer, nessa etapa de escolarização, o foco no uso social dessa prática, em detrimento do trabalho centrado exclusivamente no desenvolvimento de competências. Implica, portanto, na superação da visão instrucional/escolarizante, calcada, predominantemente, em práticas de ensino centradas na relação entre sons e letras e no treino para o reconhecimento desses sons e sua representação gráfica (VIGOTSKI, 2010). Implica, ainda, reconhecer a linguagem escrita como uma atividade social constitutiva do sujeito e das relações sociais, na qual o outro assume papel fundamental na constituição da consciência e na relação do sujeito com a realidade (BAKHTIN, 2016; VOLÓCHINOV, 2017).

A esse respeito, Geraldi (2010) enfatiza que a linguagem, compreendida como atividade constitutiva, pressupõe considerar a sua historicidade e a constituição contínua do sujeito, pois não existe uma língua pronta e rígida, assim como não existe um sujeito pronto e acabado. A constituição da língua e do sujeito se entrelaça, continuamente, nos contextos singulares em que os discursos são gerados, na interação com outros sujeitos, tecendo uma cadeia discursiva, na medida em que os enunciados proferidos nas interações imediatas são perpassados por outros enunciados que já foram proferidos em outras situações interacionais, portanto carregados de múltiplas vozes e sentidos, em dialogismo, no qual a alteridade se constitui nessas/pelas vozes que se enredam no diálogo, no encontro com o outro.

Nesse encontro, ao vivermos e reagirmos às palavras do outro, constituímos as nossas próprias, o que implica assumirmos uma posição responsiva ativa, pois “[...] a palavra constitui justamente o produto da interação do locutor e do ouvinte" (VOLOCHÍNOV, 2017, p. 117, grifo do autor). Nas palavras de Miotello (2014, p. 69), “[...] não se trata de um encontro entre eu e tu, mas antes se trata de um encontro de palavras, encontros de signos. Prenhes de valores".

À luz desses pressupostos, “[...] compreender é reagir à palavra do outro, opor à palavra do outro uma contrapalavra [...]. A compreensão não está no interior dos sujeitos, mas na relação estabelecida entre eles por meio de interação" (TAMURA, 2018, p. 33), num continuo dialogismo em que as palavras do outro nos altera, num movimento de refração, de maneira que os sentidos só se constroem nas relações dialógicas.

Sob essa compreensão, a linguagem, tomada como prática social discursiva e lugar de constituição do sujeito (FARACO, 2009; BAKHTIN, 2016; VOLOCHÍNOV, 2017), pressupõe, em relação à esfera escolar, o ensino e a aprendizagem da linguagem escrita em situações dialógicas, nas quais o professor assume importante papel mediador. 
Isso implica compreender, especificamente em relação à Educação Infantil, sujeito e linguagem entrelaçados e articulados em/nas práticas escolares marcadas pela heterogeneidade que, consequentemente, também marcarão os distintos modos de apropriação do conhecimento, por parte das crianças, cujas diferenças, como constitutivas do humano, podem e devem ser valorizadas no trabalho educativo.

Nessa direção, a reflexão acerca das implicações da lógica medicalizante no contexto da Educação Infantil assume relevância, bem como a discursivização sobre as "doenças do não aprender" nesse ambiente educacional, pois, a depender da maneira como essa temática é compreendida e enfrentada nesse ambiente, pode se constituir num entrave aos processos de ensino e aprendizagem. Isso pode ser agravado se considerarmos a antecipação do ensino da escrita e o aumento de encaminhamentos de crianças que vivenciam a apropriação formal dessa modalidade de linguagem para serviços e/ou profissionais de saúde, justificados por queixas apresentadas por seus professores relacionadas ao não aprender, cujas causas frequentemente têm sido atribuídas à criança, sem a apropriada reflexão acerca da multiplicidade de fatores implicados no processo de apropriação dessa modalidade de linguagem.

Essa situação nos leva a questionar: o que dizem os professores da Educação Infantil frente às "doenças do não aprender" considerando o contexto educacional inclusivo? Bem como a supor que, frente a esse contexto, a formação docente, mais do que nunca, necessita problematizar a temática ora em discussão, com vistas ao aprofundamento e compreensão sobre o processo de transformação de questões sociais e educacionais que culminam na individualização do insucesso escolar que permeia a trajetória acadêmica das crianças consideradas, por seus professores, como as que não aprendem.

Diante dessa problemática, questionamentos e suposição, este estudo objetivou compreender como cinco professoras que lecionam para turmas do Infantil II, de uma escola municipal de Educação Infantil, de um município de pequeno porte do interior paulista, discursivizam as "doenças do não aprender" e as possíveis implicações em sua prática docente.

\section{Percurso Metodológico}

Para a consecução do objetivo proposto, o percurso metodológico aqui empreendido reporta-se a uma das ações que integrou o projeto "Linguagem escrita e medicalização da educação: implicações nas práticas pedagógicas de professores da Educação Infantil”, 
desenvolvido desde 2015, subsidiado por princípios da abordagem colaborativa (GIROTO; CASTRO, 2011).

Sob essa abordagem, protagonizaram essa ação cinco professoras, com idade entre 24 a 56 anos e tempo de exercício no magistério entre nove e 17 anos, que atuavam em classes de Infantil II, com crianças na faixa etária de cinco anos, numa escola municipal de Educação Infantil, de um município de pequeno porte do interior paulista, conforme mencionado anteriormente.

Cabe ressaltarmos que tal escola foi particularizada, neste estudo, em razão da peculiar situação em que esses docentes se encontravam, por ocasião do processo de geração de dados aqui destacados. Haviam integrado uma formação continuada, no primeiro semestre letivo, anterior à participação no projeto acima mencionado, oferecida pela gestão dessa escola, sobre dificuldades de aprendizagem, ocasião em que o profissional da saúde que realizou essa formação também aplicou protocolos para identificação precoce de características que poderiam pressupor quadros de dislexia e/ou Transtorno de Déficit de Atenção com Hiperatividade (TDAH), bem como os instruiu acerca de práticas a serem adotadas, caso se deparassem com condições preditivas desses quadros, conforme o referencial teóricometodológico utilizado nessa formação.

Frente a isso, esses professores passaram a se preocupar, a partir de então, com a identificação precoce desses quadros, o que aumentou significativamente o número de encaminhamentos, para serviços e/ou profissionais da saúde, no município sede dessa escola (a única de Educação Infantil nesse município), de crianças com suspeita de dislexia e TDAH na faixa etária de cinco anos, matriculadas nas classes de Infantil II para as quais lecionavam. O que levou a gestão da escola a participar de uma palestra sobre desmedicalização da educação, realizada no âmbito do projeto anteriormente citado, na instituição de ensino superior na qual se encontrava sediado, ocasião em que solicitou-se a participação das cinco professoras desta escola no mesmo, com vistas a conhecerem outras abordagens sob as quais as questões de leitura e escrita poderiam ser compreendidas, quando relacionadas ao não aprender.

Como as professoras residiam num município e a sede do projeto se encontrava localizada em outro, isso dificultava a participação presencial nas atividades previstas, o que motivou a proposição de atividades a serem realizadas não apenas presencialmente, mas também em ambiente virtual. 
Desse modo, a geração dos dados aqui considerados caracterizou a atividade inicial realizada com essas professoras num fórum virtual de discussão, nomeado "Doenças do "não aprender’ e Educação Infantil na perspectiva inclusiva”, norteado pela problematização acerca da compreensão dessas professoras sobre as "doenças do não aprender", uma vez que se tratava do assunto que as mobilizava naquele momento e nos interessava partir do tema pelo qual mais se identificavam, visando o delineamento de suas expectativas e conhecimentos prévios sobre essa temática.

Todas receberam um convite on line, encaminhado em seus respectivos $e$-mails, com login e senha para acesso a esse ambiente virtual, ocasião em que manifestaram concordância com a participação voluntária no estudo, bem como preencheram um cadastro com informações sobre idade, tempo de experiência no magistério, formação inicial e continuada. Foram orientadas a se manifestarem livremente sobre o tema, bem como foi explicado que as manifestações nesse fórum subsidiariam as discussões e ações das quais, posteriormente, participariam colaborativamente no referido projeto.

Esse fórum foi realizado, na ocasião, na Plataforma Teleduc, uma vez que as professoras já tinham familiaridade com o uso dessa plataforma. Acordamos com as protagonistas que poderiam se manifestar no fórum quantas vezes desejassem, bem como poderiam se expressar livremente, sem interferência de um pesquisador/mediador, o que garantiu o dialogismo entre os próprios professores, em detrimento do monologismo característico de procedimentos tais como questionário, formulário ou protocolo com indagações fechadas, características de um discurso monologizante. Pois, num discurso monologizante, “[...] as infinitas vozes que ecoam no/do encontro dialogado se apagariam, o que, sob a concepção dialógica da linguagem, não faz sentido”. Acaba por privar “[...] o movimento ininterrupto da linguagem e as réplicas do diálogo, além de limitar os espaços de registro das respostas" (TAMURA, 2018, p. 46).

Para a análise, foi particularizada uma situação dialógica da qual todas as professoras participaram e que, sob nossa compreensão, reuniu elementos que permitiram indiciar os eixos: Concepções sobre "doenças do não aprender", que compreendeu os dados sobre como enunciaram as "doenças do não aprender"; e Prática docente frente às "doenças do não aprender", que abrangeu os enunciados acerca das ações por elas realizadas junto aos alunos considerados como os que apresentam "doenças do não aprender", às suas respectivas famílias, à escola e a si próprias. 


\section{Resultados e Discussão}

Optamos pela apresentação, na íntegra, da situação dialógica à qual nos referimos anteriormente, com vistas à apreensão desse contexto discursivo, conforme a transcrição abaixo dos enunciados que o constituíram. O consideramos revelador de elementos que indiciaram a lógica medicalizante sob a qual se encontram assentadas tanto as concepções das professoras, quanto sua atuação frente às “doenças do não aprender”, bem como orientamos nossa discussão a partir desses dois eixos de análise mencionados.

M: Eu achava que estava sabendo identificar as "doenças do não aprender", é esse nome né que estamos usando aqui. Faz muito pouco tempo que eu entrei nesse projeto, então eu ainda estou me inteirando das leituras e me organizando melhor. Pra mim doenças do não aprender é tudo que atrapalha a aprendizagem do aluno, desde as dificuldades pra ler e escrever, a falta de atenção. No semestre passado fizemos um curso e a fono explicou que temos que identificar as crianças com possível risco para dislexia e TDAH, então na medida em que vejo os problemas que as crianças apresentam eu procuro encaminhar para o médico, que aí vai dar o diagnóstico né e ver se a criança precisa de remédio ou de algum outro tratamento. A escola, a gente precisa né dar alguma resposta pra esses problemas. Precisamos encaminhar né.

L: Eu penso mais ou menos como a M também. Pra mim "doenças do não aprender" é tudo que interfere na aprendizagem, como, por exemplo, a dificuldade de concentração, a dificuldade para ler, a dificuldade para reconhecer as letras, até porque nós já estamos praticamente no fim do segundo semestre e já era para estarem lendo sim palavras, frases mais curtas e até textos mais curtos e eu tenho uns três que não conseguem ler nada ainda, ler bem, com ritmo não conseguem. Um deles ainda tem dificuldade pra reconhecer as letras do próprio nome. E não é problema pra enxergar não porque todos passaram naquele projeto com o oftalmo $e$ quem precisava de óculos já foi atendido. Mas eu ainda não mandei ninguém para o médico não porque acho que nesse fim de ano vai ser difícil agendamento.

G: Então, mas se você ficar demorando muito para encaminhar aí que vai demorar mais ainda pra conseguirem consultar. Vai que algum desses três precise de medicamento? E se precisa tem que tomar remédio pra melhorar a atenção e a memória. Vocês viram que eu enviei uma mensagem pra vocês no whtasapp sobre como identificar as crianças com dislexia? Bate tudo com o que apendemos naquele curso. Eu também separei uma reportagem que saiu numa revista com dicas que ajudam. Vou fazer cópia pra vocês. Pode ajudar.

L: Eu vi. Eu vou querer uma cópia sim. Eu estou procurando primeiro falar com as famílias conforme vou identificando os que têm problemas pra aprender e ver como farão. Porque acho que esse é o papel da escola. Temos que buscar uma solução para esses problemas. Precisamos envolver a família. Se a familia também não fizer nada aí não dá pra gente ajudar sozinho.

G: É bom não demorar muito porque já vão com defasagem para o primeiro ano e vai acabar sobrando pra você, porque as famílias não 
ajudam em nada e acabam jogando a culpa no professor, só sabem cobrar da escola, mas sempre têm desculpa para não comparecer aqui quando a gente chama.

L: E eu não sei? Sempre sobra pra gente.

O: Eu gostei muito das dicas, até estou aproveitando algumas, assim como as dicas que aprendemos no curso que fizemos. Outro dia também vi uma reportagem sobre isso com dicas muito boas. Temos que ficar atentas porque as crianças que já trocam na fala podem trocar na escrita $e$ desenvolverem uma dislexia. Eu tenho um aluno que eu considero com "doença do não aprender". Lê muito devagar e tem que ficar voltando toda hora porque esquece o que leu, ele também fala errado. Vai ter que fazer aquele trabalho do processamento auditivo, que vai ser bom para melhorar $a$ atenção, que ela falou. Acho que melhora a memória também. Eu já pedi para a família levar no médico e a mãe mandou um bilhete avisando que o médico do postinho já encaminhou para o neurologista e agora tem que aguardar. Eu já coloquei isso no prontuário dele. Temos que registrar porque assim podemos acompanhar o histórico dessas crianças.

P: Na minha turma eu também tenho crianças com esses mesmos problemas que vocês estão falando aqui. Nem estou falando das crianças com deficiências. Com deficiência eu tenho uma criança com síndrome e outra que é surda. Essas não me dão trabalho porque já frequentam a sala de recursos e eu não preciso me preocupar. Mas tenho três que me preocupam mais. Tem uma que quando eu peço pra ler e quando você pergunta o que entendeu do que leu não é capaz de interpretar o que leu, nem frases consegue entender, pode ser sim um caso de dislexia no futuro, como vimos ou alguma outra "doença do não aprender". Os outros dois têm muita dificuldade em se concentrarem nas atividades. Esses eu já pedi para os pais procurarem o médico porque acho que precisarão tomar remédio porque são muito agitados. Acho que vão precisar tomar a ritalina. Não prestam atenção e atrapalham bastante a turma. Quando vou pegar o caderno de atividades para verificar sempre tem pouca coisa escrita. Eu insisto, explico que tem que escrever, mas não adianta. Um deles quando escreve tudo junto, o pouco que consegue escrever é bem difícil de entender. A mãe falou que ele gosta de ler gibi, mas eu já pedi pra ele ler gibi aqui e ele não se interessou. Acho que na verdade ele só fica olhando as figuras. Eu tomo a leitura e ele diz que não quer ler, que não sabe. Esse está bem atrasado nas atividades, pode ser sim um problema no cérebro. (grifos nossos).

\section{Concepções sobre as "doenças do não aprender"}

A partir dos enunciados gerados nessa situação dialógica, que circularam em torno da temática proposta, particularizamos elementos que compreendemos como indícios das concepções que as professoras apresentaram sobre as "doenças do não aprender".

Inicialmente destacamos que, em nenhum momento, as professoras questionaram o uso da expressão “doenças do não aprender” nesse fórum de discussão. Pareceram acatar o uso dessa expressão com naturalidade, compreendendo-a atrelada a um ideal normalizador já refratado em seus discursos. Sequer apresentaram suposições ou informações que sugerissem 
outra forma de compreensão acerca dessa temática ou mesmo fizeram referências sobre os processos de ensino e aprendizagem que remetessem à compreensão de linguagem escrita como prática discursiva (GERALDI, 2010) e à criança como produtora de cultura (BAPTISTA, 2010).

Ao contrário, reforçaram ideias atreladas à transformação de questões de ordem social, cultural e política em questões biológicas, cuja solução tem sido deslocada para o campo médico, que configura o processo de medicalização da vida em suas diferentes esferas, sob o qual as desigualdades socialmente produzidas são reduzidas ao aspecto individual, compreendidas, portanto, desatreladas do contexto sócio-histórico em que os sujeitos encontram-se inseridos. Portanto, distantes das realidades que vivenciam (MOYSÉS, 2001; PARRAT-DAYAN, 2012).

Os enunciados encontravam-se impregnados de referências à formação da qual haviam participado, conforme os excertos aqui destacados: “[...] No semestre passado fizemos um curso e a fono explicou que temos que identificar as crianças com possível risco para dislexia e TDAH” (M); “[...] assim como as dicas que aprendemos no curso que fizemos" (L); e "[...] pode ser sim um caso de dislexia no futuro, como vimos" $(P)$.

Indícios do quanto essa lógica normalizadora e medicalizante tem se refratado nesse contexto foram observados nos enunciados que circularam em torno dessa perspectiva, uma vez que ressaltaram aspectos subjetivados do discurso médico/clínico, tais como: "[...] e ver se a criança precisa de remédio ou de algum outro tratamento" (M); “[...] Vai que algum desses três precise de medicamento? E se precisa tem que tomar remédio pra melhorar a atenção e a memória" (G), ao referirem, particularmente, à ação de identificação de características preditivas que, sob a compreensão medicalizante, compõem o que compreenderam como "doenças do não aprender".

Em igual medida observamos a subjetivação não só do discurso médico/clínico, mas daquele veiculado, superficialmente, pelas mídias sociais, com aligeiradas considerações sobre a temática, exemplificada por excertos dos enunciados aqui considerados, tais como: "[...] Vocês viram que eu enviei uma mensagem para vocês no whtasapp sobre como identificar as crianças com dislexia? Bate tudo com o que apendemos naquele curso. Eu também separei uma reportagem que saiu numa revista com dicas que ajudam” (G); e "[...] Outro dia também vi uma reportagem sobre isso com dicas muito boas” (O).

Tal subjetivação, nas palavras de Tesser e Neto (2010, p. 281), exige intenso trabalho voltado à "[...] desmedicalização do imaginário dos pais e profissionais", o que requer que a 
multiplicidade de aspectos que permeiam a condição de "doença do não aprender" seja compreendida e contextualizada também sob "[...] a relação entre pais e filhos, entre irmãos, dinâmica familiar e de relações sociais, presença-ausência dos pais, situação social e cultural, bem como econômica dos mesmos" e não meramente individualizados, naturalizados e circunscritos a problemas orgânicos.

As "doenças do não aprender" foram concebidas como o comprometimento de questões de leitura e escrita, tais como: a representação da relação fonema-grafema, ao enunciarem "[...] tudo que atrapalha a aprendizagem do aluno, desde as dificuldades pra ler e escrever” (M), “[...] dificuldade para ler, a dificuldade para reconhecer as letras [...] dificuldade pra reconhecer as letras do próprio nome” (L), "[...] trocam na fala podem trocar na escrita e desenvolverem uma dislexia" (O); e a velocidade de leitura, mencionada por L, quando referiu que "[...] não conseguem ler bem, com ritmo".

Assim como as relacionaram a questões de atenção, concentração e memória, exemplificadas pelos excertos "[...] falta de atenção” (M), "[...] dificuldade de concentração" (L), "[...] tem que ficar voltando toda hora porque esquece o que leu [...] Vai ter que fazer aquele trabalho do processamento auditivo, que vai ser bom para melhorar a atenção, que ela falou. Acho que melhora a memória também” (O); do cérebro: “[...] problema no cérebro" (P). Bem como as relacionaram à questão da compreensão leitora, quando uma das professoras mencionou "[...] não é capaz de interpretar o que leu [...] nem frases consegue entender" $(O)$ e às questões comportamentais, a exemplo do excerto "[...] são agitados [...] atrapalham bastante a turma” $(P)$.

Moysés e Collares (2010, p. 54) ressaltam que a medicalização se constitui num processo de normalização que resulta nas "doenças do não aprender" e "não se comportar", frequentemente justificadas por questões de fala, leitura, escrita e comportamentos que retratam modos distintos de constituição dos sujeitos que se distanciam do que é desejado sob o ideal de normalidade homogeneizador, "[...] isentando de responsabilidades todas as instâncias de poder, em cujas entranhas são gerados e perpetuados tais problemas".

Sob tais elementos, nos pareceu apropriado considerar que a lógica medicalizante foi fortalecida no discurso das professoras também sob a ótica da culpabilização pelo insucesso escolar, atribuído ora à criança ora às suas famílias, conforme expressaram nos excertos “[...] Se a família também não fizer nada” (L), "[...] porque as famílias não ajudam em nada” (G).

Moysés (2001) destaca a necessidade de superação dessa visão individualizante, biologizante e medicalizante, à qual a sociedade contemporânea encontra-se submetida e sob 
a qual questões sociais e subjetivas são deslocadas para o campo médico, por meio da reflexão sobre o processo de apropriação de conhecimentos, compreendido numa dimensão coletiva, em detrimento da culpabilização também individualizada, ora atribuída à criança ou às suas famílias, ora sob responsabilidade do professor ou da escola.

Na situação dialógica considerada, a culpabilização atribuída ao professor e à escola nos pareceu implicitamente manifestada, como no excerto "[...] acabam jogando a culpa no professor, só sabem cobrar da escola” (G). Situação destacada por Collares e Moysés (2010, p. 250) como uma grande incoerência, pois “[...] como podem ser todos culpados, individualmente? Se todos têm culpas, o problema torna-se, conceitualmente, coletivo".

$\mathrm{Na}$ perspectiva vigotskiana (VIGOTSKI, 2010), o processo de apropriação da linguagem escrita é marcado pela descontinuidade e heterogeneidade, o que parece ser desconsiderado quando nos remetemos a elementos como "[...] nós já estamos praticamente no fim do segundo semestre e já era para estarem lendo sim palavras, frases mais curtas e até textos mais curtos e eu tenho uns três que não conseguem ler nada ainda” $(L)$.

Pareceu prevalecer, atrelada à compreensão sobre as "doenças do não aprender" manifestada na situação dialógica considerada, uma perspectiva reducionista de linguagem escrita, centrada em competências descontextualizadamente consideradas, em detrimento da compreensão de escrita como prática social discursiva, cuja apropriação se dá nas/pelas relações humanas constituídas nas práticas sociais em que o uso social dessa modalidade de linguagem é valorizado.

De modo que a compreensão sobre as "doenças do não aprender" manifestada pelas professoras que protagonizaram esse estudo reforça a necessidade de se repensar essa temática do ponto de vista, dentre outros aspectos, do lugar que tem ocupado na educação, ao ser, frequentemente, deslocada para o campo da saúde, bem como da relação com a prática docente, submetida ao discurso médico/clínico. Relação essa particularizada a seguir.

\section{Prática docente frente às "doenças do não aprender"}

A desresponsabilização da escola e, consequentemente, do professor acerca da posição assumida frente às "doenças do não aprender" é aqui tematizada, a partir do destaque a dois aspectos: a adoção de práticas do campo da saúde, em especial de encaminhamentos para obtenção de laudos e/ou prescrição de medicamentos, e o trabalho educativo esvaziado 
de sentido, que pareceu ter sido manifestado, explícita ou implicitamente, nos enunciados das professoras.

A prática de encaminhamentos aos serviços e/ou profissionais da saúde, por parte das professoras, sem uma cuidadosa e aprofundada reflexão acerca das questões que compreenderam como características preditivas de "doenças do não aprender", reforçaram a suposição de que a prática docente, tal como essa compreensão, também tem ocorrido sob o ideal de normalidade homogeneizador e medicalizante.

As professoras manifestaram uma concepção reducionista sobre o papel mediador do professor no trabalho educativo, na Educação Infantil na perspectiva inclusiva, conforme expresso nos excertos: “[...] temos que identificar as crianças com possível risco para dislexia e TDAH, então na medida em que vejo os problemas que as crianças apresentam eu procuro encaminhar para o médico, que aí vai dar o diagnóstico né e ver se a criança precisa de remédio ou de algum outro tratamento” (M); “[...] Mas eu ainda não mandei ninguém para o médico não porque acho que nesse fim de ano vai ser difícil agendamento" (L); “[...] Então, mas se você ficar demorando muito para encaminhar aí que vai demorar mais ainda pra conseguirem consultar. Vai que algum desses três precise de medicamento? E se precisa tem que tomar remédio pra melhorar a atenção e a memória” (G); “[...] pedi para a família levar no médico e a mãe mandou um bilhete avisando que o médico do postinho já encaminhou para o neurologista e agora tem que aguardar. Eu já coloquei isso no prontuário dele” (O); e “[...] pedi para os pais procurarem o médico porque acho que precisarão tomar remédio porque são muito agitados. Acho que vão precisar tomar a ritalina” $(P)$.

Welch et al., (2008) chamam a atenção para o crescimento vertiginoso e epidêmico de diagnósticos gerados pelo processo de medicalização da vida, na sociedade contemporânea.

Se considerarmos os índices de encaminhamentos, oriundos das escolas, de crianças em processo de apropriação da linguagem escrita com suspeita de "doenças do não aprender" e de consumo de psicotrópicos frequentemente utilizados por essas crianças em idade escolar (MOYSÉS; COLLARES, 2010), é possível percebermos o impacto dessa medicalização da vida no âmbito educacional, o que parece ser corroborado pelos elementos destacados dos enunciados das professoras. Suposição fortalecida pela referência não apenas a encaminhamentos predominantemente externos à escola, mas também à expectativa de uso de medicação e/ou de realização de tratamento, como se esses, por si só, fossem dar conta de 
devolver essas crianças à escola alfabetizadas e com as questões comportamentais e de leitura e escrita solucionadas.

Não descartamos a possibilidade, em alguns casos, de comprometimentos do corpo corroborarem com a precarização das condições de apropriação de conhecimentos. Entretanto, Legnani e Pereira (2015) ressaltam o caráter mercadológico sob o qual intensos investimentos em consultas médicas e medicamentos buscam responder à lógica medicalizante.

Situação agravada pela espetacularização da mídia acerca desses investimentos, não apenas na divulgação de informações superficiais e aligeiradas sobre quadros que os professores compreendem como "doenças do não aprender", a exemplo da dislexia, conforme mencionado anteriormente, como na busca pela normalidade que, frente às desigualdades sociais, está longe de ser alcançada. Mesmo porque esse padrão de normalidade, invariavelmente, corresponde aos anseios de uma sociedade marcada pela luta de classes, revezando-se no poder e controle dos aspectos políticos e econômicos de grupos sociais que alcançam prestígio, conforme determinada época e lugar, que defendem posicionamentos ideológicos sob os quais se encontram implicadas concepções sobre sujeito, educação, saúde, ensino, aprendizagem, entre outras, determinantes para se investir mais ou menos nessa busca por esse ideal normalizador homogeneizador.

Mais recentemente, esses índices alarmantes deflagraram ações governamentais direcionadas à redução da excessiva medicalização de jovens e adultos, resultando em recomendações sobre esse tema (FÓRUM SOBRE A MEDICALIZAÇÃO DA EDUCAÇÃO E DA SOCIEDADE BRASIL, 2015), ainda que tais recomendações não tenham sido intensivamente adotadas na educação, de forma geral, e na Educação Infantil, em especial (MARQUES, 2018).

Essa situação é ainda mais agravada pela precarização da formação de profissionais nos campos da saúde e da educação, principalmente daqueles que sequer tiveram, em sua formação inicial, qualquer conteúdo problematizando os malefícios da equivocada e contínua medicalização da vida e da educação. Esse processo está tão naturalizado na sociedade que não se encontra restrito ao campo médico, pois, com a proliferação alarmante de diagnósticos de "doenças do não aprender", proliferaram também profissões e profissionais que atuam com essas "doenças", a partir dessa individualização de aspectos dos processos de ensino e aprendizagem, deflagrando a patologização desses processos.

Fonoaudiólogos, psicólogos, psicopedagogos, por exemplo, juntam-se, em grande número, ao campo médico, para instituir e/ou legitimar rótulos superficialmente construídos 
acerca dos escolares e de suas demandas educacionais, sem se proporem à compreensão aprofundada sobre a complexidade que tais processos assumem no desenvolvimento humano.

É curioso que, embora tenham feito referências a encaminhamentos realizados no âmbito da própria escola, a exemplo do encaminhamento de crianças com deficiências ao professor especialista, para o atendimento educacional especializado: "[...] Nem estou falando das crianças com deficiências. Com deficiência eu tenho uma criança com síndrome e outra que é surda. Essas não me dão trabalho porque já frequentam a sala de recursos e eu não preciso me preocupar" $(P)$, esse encaminhamento, tal como aqueles realizados para o campo clínico, remete à desresponsabilização frente ao trabalho educativo.

Em última instância, talvez até pudéssemos considerar que a única responsabilidade que vislumbram e que, inclusive, confunde-se com a prática docente frente às "doenças do não aprender", é o próprio ato de encaminhamento/deslocamento dessa questão para o campo clínico, manifestado mesmo quando referem que "[...] Temos que buscar uma solução para esses problemas" (L). A própria menção ao ato de registrar esses procedimentos, "[...] já coloquei isso no prontuário dele. Temos que registrar porque assim podemos acompanhar o histórico dessas crianças" $(O)$, reforça tal suposição.

A documentação pedagógica, que poderia se constituir numa importante prática discursiva acerca do processo educativo, tem sido reduzida ao registro dos problemas, encaminhamentos e medicamentos vinculados a esse modo de agir dos professores frente às doenças do não aprender. Inclusive com o emprego de expressões características do campo médico, como a expressão prontuário, sendo esse registro tomado sob a compreensão de uma espécie de justificativa que desonera o professor de sua responsabilização - a mediação - no trabalho educativo.

É possível supor que as crianças com as quais atuam estejam sendo expropriadas do lugar de atores sociais, produtores de cultura (BAPTISTA, 2010), da condição de sujeitos que falam/leem, mas também que precisam ser escutados/lidos, num processo contínuo e dialógico de construção do conhecimento e, consequentemente, de aprendizado.

De maneira que, tanto a atividade, por parte desses sujeitos, quanto o ensino de conhecimentos valorizados socialmente, são necessários para que o processo educativo ocorra no nível do desenvolvimento proximal, ou seja, naquilo que não foi internalizado e que, sob mediação, possibilite a internalização do que foi ensinado (VIGOTSKI, 2000). Isso pressupõe, então, situações de aprendizagem nas quais sejam valorizadas as especificidades de cada um, nas quais ocorra, de fato, interação entre interlocutores que adotam uma posição 
de responsividade/atividade, ao responderem ao enunciado um do outro, atuando na e com a linguagem (GERALDI, 1997; BAKHTIN, 2016).

Sob esse caráter heterogêneo, o trabalho educativo requer práticas pedagógicas voltadas para a apropriação da linguagem escrita assentadas na compreensão de linguagem que valoriza a inserção dos sujeitos em práticas sociais de uso dessa modalidade, em detrimento de um ensino centrado, exclusivamente, em práticas mecanicistas que envolvem treino e repetição, descontextualizadas e desprovidas de sentidos para as crianças, muitas vezes centradas apenas nos aspectos formais da língua, que não valorizam a reflexão sobre a linguagem, uma vez que o ensino precisa ser orientado, tal como proposto por Geraldi (1997), pelo "uso social" da linguagem.

Isso implica no dialogismo necessário e inerente aos atos de leitura e escrita. Requer interação, interlocução, sendo o papel mediador do professor, nesse processo, preponderante para tal reflexão, não apenas na promoção de situações discursivas que o favoreçam, mas também em relação ao modo como realiza essa mediação (SMOLKA, 2012), estreitamente alinhado às suas concepções de ensino e aprendizagem, de sujeito, de linguagem, de inclusão, dentre outras.

\section{Considerações finais}

A discussão empreendida nesse artigo priorizou a discursivização, por parte de professores de Educação Infantil, sobre as "doenças do não aprender" e sua prática docente frente a tais "doenças".

Dessa relação depreenderam-se elementos que nos permitiram considerar que, na Educação Infantil, ao menos no que diz respeito ao contexto enunciativo-discursivo da escola e protagonistas considerados, foram indicadas tanto uma compreensão quanto uma prática sobre as "doenças do não aprender", predominantemente constituídas sob o ideal normalizador homogeneizador e medicalizante, do qual resultou a desresponsabilização docente. Ao proporem e incentivarem o deslocamento de questões sociais e/ou educacionais para a clínica, num processo de subjetivação desse ideal normalizador constituído no campo médico, as professoras demonstraram não estar preparadas para lidar com os distintos modos de apropriação de conhecimentos por parte da heterogeneidade de sujeitos que frequentam as escolas, o que inviabilizou considerarem as especificidades das crianças com as quais atuam. 
Nesse contexto, faz-se necessário o resgate do papel do professor de Educação Infantil quanto ao acolhimento da criança que irá se deparar com a apropriação formal dos conhecimentos veiculados na/pela escola, nessa modalidade educacional, uma vez que suas concepções e ações, no processo de mediação, direcionarão a prática docente não apenas quanto ao trabalho educativo voltado à apropriação da linguagem escrita, mas também frente às “doenças do não aprender”.

O conhecimento desses professores acerca dessa temática assume relevância, se for identificada a necessidade de preparação desse professor para lidar com a heterogeneidade das crianças e, consequentemente, com suas diferenças, bem como com a mudança de sua conduta, quanto à melhora da qualidade dos processos de ensino e aprendizagem, no que se refere à promoção e mediação de práticas discursivas que impactem na apropriação da escrita, numa perspectiva dialógica, se este profissional possibilitar aos seus alunos o acesso a condições favoráveis à aprendizagem dessa modalidade de linguagem.

Isso poderá se constituir em um importante argumento para a desmedicalização do ambiente escolar e para que o professor assuma o seu lugar de direito na educação, em detrimento da valorização de ações equivocadas de profissionais que, habitualmente, atribuem aos modos singulares com que as crianças enfrentam a apropriação da escrita causas exclusivamente biológicas, expropriando-as do direito à educação de qualidade e, principalmente, de terem suas diferenças apropriadamente consideradas no contexto educacional inclusivo.

\section{REFERÊNCIAS}

BAKHTIN, M. Os gêneros do discurso. Organização, tradução, posfácio e notas de Paulo Bezerra; notas da edição russa de Serguei Botcharov. São Paulo: Editora 34, 2016.

BAPTISTA, M. C. A linguagem escrita e o direito à educação na primeira infância. Anais do I Seminário Nacional: Currículo em Movimento - Perspectivas atuais, Belo Horizonte, p. 112. 2010. Anais...belo Horizonte, 2010.

CANGUILHEM, G. O Normal e o patológico. Rio de Janeiro: Forense Universitária, 2000.

CHRISTOFARI, A. C. Modos de ser e de aprender na escola: medicalização (in) visível? (Tese de Doutorado). Rio Grande do Sul: Universidade Federal do Rio Grande do Sul. 2014.

FARACO, C. A. Linguagem \& diálogo: as ideias linguísticas do círculo de Bakhtin. São Paulo: Parábola Editorial. 2009. 
FÓRUM SOBRE A MEDICALIZAÇÃO DA EDUCAÇÃO E DA SOCIEDADE. Recomendações de práticas não medicalizantes para profissionais e serviços de educação e saúde. 2015. Disponível em: https://site.cfp.org.br/wp-

content/uploads/2015/06/CFP_CartilhaMedicalizacao_web-16.06.15.pdf. Acesso em: 22 jul. 2018.

FRANCES, A. Voltando ao normal: como o excesso de diagnósticos e a medicalização da vida estão acabando com a nossa sanidade e o que pode ser feito para retomarmos o controle. Rio de Janeiro: Versal Editores. 2016.

GERALDI, J. W. Portos de passagem. São Paulo: Martins Fontes, 1997.

GERALDI, J. W. A aula como acontecimento. São Carlos: Pedro e João Editores, 2010.

GIROTO, C. R. M. A parceria entre o professor e o fonoaudiólogo: um caminho possível para a atuação com a linguagem escrita. Marília, 2006, 256 f. Tese. (Doutorado em Educação). FFC - UNESP, 2006.

GIROTO, C. R. M.; CASTRO, R. M. A formação de professores para a Educação Inclusiva: alguns aspectos de um trabalho colaborativo entre pesquisadores e professores da Educação Infantil. Rev. Educ. Espec., v. 24, n. 41, p. 441-452, 2011.

GIROTO, C. R. M.; BERBERIAN, A. P.; SANTANA, A. P. Salud, Educación y Educación Especial: principios y paradigmas guías de las prácticas en salud en el contexto educativo inclusivo. In: GIROTO, C. R. M. et al. (Org.). Servicios de apoyo en Educación Especial: una mirada desde diferentes realidades. Alcalá de Henares/Espanha: Servicio de Publicaciones de la Universidad de Alcalá de Henares, 2014, p. 115-138.

GUARRIDO, R. A Biologização da vida e algumas implicações do discurso médico sobre a educação. In: Conselho Regional de Psicologia/SP; Grupo Interinstitucional Queixa Escolar/SP. (Orgs.). Medicalização de crianças e adolescentes: conflitos silenciados pela redução de questões sociais a doenças individuais. São Paulo: Casa do Psicólogo, 2010; p. 27 40.

MARQUES, J. B. Os sentidos do não aprender na perspectiva de alunos do ensino fundamental I, professores e familiares. Araraquara, 2018, 154 f. Dissertação. (Mestrado em Educação Escolar). FCLAr - UNESP, 2018.

MIOTELLO, V. A consciência que se alarga. In: GRUPO DE ESTUDOS DOS GÊNEROS DO DISCURSO - GEGe. Palavras e contrapalavras: constituindo o sujeito em alteração. São Calos, SP: Pedro \& João Editores, 2014, p. 68-72.

MOYSÉS, M. A. A. A institucionalização invisível: crianças que não-aprendem-na-escola. Campinas, SP: Mercado de Letras, 2001.

MOYSÉS, M. A.; COLLARES, C. A. L. Dislexia e TDAH: uma análise a partir da ciência médica. In: Conselho Regional de Psicologia de São Paulo (Org.). Medicalização de crianças e adolescentes: conflitos silenciados pela redução de questões sociais a doença de indivíduos. São Paulo: Casa do Psicólogo, 2010, p. 125-156. 
MOYSÉS, M. A.; COLLARES, C. A. L. Medicalização: o obscurantismo reinventado. In: COLLARES, C.A.L.; MOYSÉS, M. A.; RIBEIRO, M. (Orgs): Novas capturas, antigos diagnósticos na era dos transtornos. São Paulo: Mercado de Letras, 2013. p.41- 64.

PARRAT-DAYAN, S. Trad. Silvia Beatriz Adoue e Augusto Juncal. Como enfrentar a indisciplina na escola. São Paulo: Contexto, 2012.

SAVIANI, D. Pedagogia histórico-crítica: primeiras aproximações. São Paulo: Cortez/Autores Associados, 1991.

SMOLKA, A. L. B. A criança na fase inicial da escrita: a alfabetização como processo discursivo. 13 ed. São Paulo: Cortez. 2012.

TAMURA, A. L. H. Concepções de professores alfabetizadores sobre leitura: implicações na formação leitora de seus alunos. Marília, 2018, 128 f. Dissertação. (Mestrado em Educação). FFC - UNESP, 2018.

VIGOTSKI, L. S. A formação social da mente. São Paulo: Martins Fontes, 2010.

VOLÓCHINOV, V. Marxismo e filosofia da linguagem: problemas fundamentais do método sociológico na ciência da linguagem. Tradução, notas e glossário de Sheila Grillo e Ekaterina Vólkova Américo. Ensaio introdutório de Sheila Grillo. São Paulo: Editora 34, 2017.

WELCH, G.; SCHWARTZ, L.; WOLOSHIN, S. O que está nos deixando doentes é uma epidemia de diagnósticos. Jornal do Cremesp, p. 12, fev. 2008. (texto publicado no The New York Times, em 02/01/2007; tradução de Daniel de Menezes Pereira).

\section{Como referenciar este artigo}

GIROTO, Claudia Regina Mosca.; ARAUJO, Luciana Aparecida de; VITTA, Fabiana Cristina Frigieri de. Discursivização sobre "doenças do não aprender" no contexto educacional inclusivo: o que dizem os professores de Educação Infantil? Revista IberoAmericana de Estudos em Educação, Araraquara, v. 14, n. esp. 1, p. 807-825, abr., 2019. EISSN: 1982-5587. DOI: 10.21723/riaee.v14iesp.1.12208

Submetido em: 06/08/2018

Aprovado em: 12/09/2018 